\title{
Impact of High Body Mass Index on Morbidity and Mortality in Cardiac Surgery
}

Etik Kurul Onayı: Bağcılar Eğitim ve Araştırma Hastanesi Girişimsel Olmayan Klinik Araştırmalar Etik Kurulu'ndan onay almıștır (2014/245).

Çıkar çatışması: Yoktur.

Finansal destek: Alınmamıştır.

Hasta onamı: Alınmıştır.
Ethics Committee Approval: Bağcılar Training and Research Hospital has been approved by the Non-Invasive Clinical Research Ethics Committee (2014/245).

Conflict of interest: None

Funding: None

Informed consent: Obtained

Cite as: Gümüş Özcan F, Demirgan S, Abdullah T, Selcan A. Kalp cerrahisinde yüksek vücut kitle indeksinin morbidite ve mortalite üzerine etkileri. GKDA Derg. 2020;26(3):165-71.

\section{Öz}

Amaç: Bu çalıșmada, vücut kitle indeksinin (VKi) kardiyak cerrahi sonrası mortalite ve morbidite üzerine etkilerini değerlendirdik.

Yöntem: Kliniğimizde açık kalp cerrahisi geçiren 813 hastanın kayıtları retrospektif olarak incelendi. Kayıtları eksiksiz olan 555 hasta çalıșmaya dahil edildi. Kayitlardan vücut kitle indeksi (VKi) $\geq 30 \mathrm{~kg} / \mathrm{m}^{2}$ ve VKi $<30 \mathrm{~kg} / \mathrm{m}^{2}$ olan hastalarda postoperatif mortalite ve morbidite gelişimleri karşılaştırıldı.

Bulgular: Hastaların 389'u (\%70) VKi< $30 \mathrm{~kg} / \mathrm{m}^{2}$ obez olmayan (Grup N), 166'sı VKi $\geq 30 \mathrm{~kg} / \mathrm{m}^{2}$ obez (Grup OB) idi. Grupların yaş ortalamaları (sırasıyla 59.2 $\pm 12.5,59.6 \pm 9.6$ yıl $p=0.65$ ) benzerdi. Kadın cinsiyet, diabetes mellitus, hipertansiyon, hiperlipidemi Grup OB'de fazla bulun$d u(p<0.05)$. Intraoperatif kardiyopulmoner baypas $(101 \pm 43,98 \pm 42 p=0.26)$, aort kros klemp (64 $\pm 32.7,61.6 \pm 32.5 p=0.21)$ süreleri benzerdi. Postoperatif pulmoner $(\% 19, \% 10)$, renal $(\% 13, \% 9)$ komplikasyonlar Grup OB'de anlamlı şekilde fazlayken ( $p<0.05)$, tamponad (\%3.1 $\% 0.6)$ ve kanama revizyonu (\%5.7, \%1.8) Grup N'de daha fazla bulundu ( $p<0.05)$. Ameliyat sonrası 27 (\%5) hastada mortalite görüldü. Mortalite oranları, yoğun bakım ve hastane kalış süreleri arasında istatistiksel anlamlı fark tespit edilmedi $(p<0.05)$.

Sonuç: Obezite, kalp cerrahisi sonrası solunum sistemi ve renal komplikasyonlarla, düşük vücut ağırlı̆ı ise tamponad ve kanama revizyonu gibi morbiditelerle ilişkilidir.

Anahtar kelimeler: kalp cerrahisi, Vücut Kitle Indeksi, obezite, morbidite, mortalite

\section{ABSTRACT}

Objective: In this study, we evaluated the effects of body mass index on mortality and morbidity after cardiac surgery.

Method: The record of 813 patients who performed open-heart surgery in our clinic were retrospectively analyzed. 505 patients with complete records were included in the study. Postoperative mortality and morbidity developments were compared in patients with a body mass index of $(B M I) \geq 30 \mathrm{~kg} / \mathrm{m}^{2}$ and $B M I \leq 30 \mathrm{~kg} / \mathrm{m}^{2}$ from the records.

Results: $389(\% 70)$ of patients were $B M I<30 \mathrm{~kg} / \mathrm{m}^{2}$, non-obese (Group N), 166 of them were $B M I \geq 30 \mathrm{~kg} / \mathrm{m}^{2}$, obese (Group OB). The mean age of groups $(59.2 \pm 12.5,59.6 \pm 9.6$ years, respectively, $p=0.65$ ) was similar. Female gender, Diabetes Mellitus (DM), hypertension, hyperlipidemia were more common in Group $O B(p<0.05)$. Intraoperative cardiopulmonary bypass $(101 \pm 43,98 \pm 42 p=0.26)$ and the duration of aortic cross clamp $(64 \pm 32.7,61.6 \pm 32.5$ $p=0.21)$ were similar. Post-operative complications of pulmonary $(\% 19, \% 10)$ and renal $(\% 13$, $\% 9)$ were significantly higher in Group $O B(p<0.05)$, tamponade $(\% 3.1, \% 0.6)$ and bleeding revision (\%5.7, \%1.8) were higher in Group N ( $p<0.05)$. Mortality occurred in $27(5 \%)$ patients after surgery. There was no significant difference between mortality rates, ICU and hospital stay $(p<0.05)$.

Conclusion: High BMI $\left(\geq 30 \mathrm{~kg} / \mathrm{m}^{2}\right)$ is associated with respiratory system and renal complications after cardiac surgery, and low $B M I\left(<30 \mathrm{~kg} / \mathrm{m}^{2}\right)$ is associated with morbidities such as tamponade and bleeding revision.

Keywords: cardiovascular surgery, Body Mass Index, obesity, morbidity, mortality
Received/Geliş: 01.09.2020

Accepted/Kabul: 08.09.2020

Published Online/Online yayın: 21.09.2020

Funda Gümüş Özcan

TC Sağlık Bakanlığı

Başakşehir Çam ve Sakura Şehir Hastanesi Anesteziyoloji ve Reanimasyon Kliniği İstanbul, Türkiye

fgumus@hotmail.com ORCiD: 0000-0003-3264-4356

S. Demirgan 0000-0001-8129-5004

A. Selcan 0000-0001-6464-4188 S.B.Ü. Bağcılar Eğitim ve Araşttrma Hastanesi

Anesteziyoloji ve Reanimasyon Kliniği İstanbul, Türkiye

T. Abdullah 0000-0002-2096-4646 TC Sağlık Bakanlığı

Başakşehir Çam ve Sakura Şehir Hastanesi Anesteziyoloji ve Reanimasyon Kliniği Istanbul, Türkiye 


\section{Giriş}

Obezite, tüm dünyada gittikçe artan ciddi bir sorun haline gelmiştir ${ }^{[1,2]}$. Obeziteyle ilişkili olarak kardiyovasküler hastalıklar yaygın olarak görülmekte ve bunun sonucu olarak da her geçen gün artan sayıda obez olguda kardiyak cerrahi planlanmaktadır ${ }^{[3,4]}$.

Obezitenin kardiyovasküler cerrahide postoperatif hasta sonuçlarına etkileri pek çok çalışmada analiz edilmiş ve farklı sonuçlarla bildirilmiştir [5-9]. Bazı çalışmalarda obezitenin, kardiyovasküler cerrahi sonrası daha yüksek mortalite ve morbiditeye neden olduğu ${ }^{[5-8]}$, bazılarında ise obezitenin kalp cerrahisi sonrası mortalite ve morbidite sonuçlarını etkilemediği, hatta obezite ile kötü hasta sonuçları arasında ters ilişki olduğu gösterilmiş ve bu durum obezite paradoksu ile açıklanmıştır ${ }^{[9-11]}$.

Obezitenin kardiyovasküler cerrahi sonrası etkileri değişkendir ve netlik kazanmamıştır ${ }^{[9]}$.

Biz de bu çalışmada, $V K i \geq 30 \mathrm{~kg} / \mathrm{m}^{2}$ ve $\mathrm{VKi}<30 \mathrm{~kg} / \mathrm{m}^{2}$ hastalarda, açık kalp cerrahisi sonrası morbidite ve mortalite gelişimlerini analiz etmeyi amaçladık.

\section{GEREÇ ve YÖNTEM}

Çalışmamızda, hastanemiz Etik Kurul Onayı (Karar Numarası: 2014-245) alınarak, 2010-2013 tarihleri arasında Bağcılar Eğitim ve Araştırma Hastanesi kalp ve damar cerrahisi ameliyathanesinde açık kalp cerrahisi operasyonu geçirmiş 813 hasta retrospektif olarak değerlendirildi. Açık kalp cerrahisi ve eşlik eden prosedürler uygulanan, perioperatif kayıtlarında eksik bulunmayan toplam 555 hasta çalışmaya dahil edildi. Değerlendirilen hastalar VKi temel alınarak yapılan obezite sınıflandırmasına göre VKi $<30$ $\mathrm{kg} / \mathrm{m}^{2}$ olan obez olmayan grup (Grup $\mathrm{N}$ ) ve VKi $\geq 30$ $\mathrm{kg} / \mathrm{m}^{2}$ olan obez (Grup OB)olmak üzere iki grup altında analiz edildi ${ }^{[12] .}$

Hastaların preoperatif demografik özellikleri; yaş, cinsiyet, VKi, ejeksiyon fraksiyonları ASA (American
Society of Anesthsiologist) fiziksel durumları, sigara kullanımı, eşlik eden hipertansiyon (HT) (kan basıncı $\geq 140 / 90 \mathrm{~mm} / \mathrm{Hg}$ veya antihipertansif tedavi kullanımı), diabet mellitus (DM) (açlık kan şekeri >200mg/dl ve antidiabetik tedavi kullanımı), hiperlipidemi (kolesterol>200mg/dl ve antilipidemik tedavi kullanımı), kronik obstrüktif akciğer hastalıkları (KOAH- spirometrik testler ile tanımlanmış veya bronkodilatör tedavi kullanımı), kronik böbrek yetmezliği (serum kreatinini $>1.5 \mathrm{gr} / \mathrm{dL}$ veya dializ gereksinimi), geçirilmiş serebrovasküler olay (SVO), tıkayıcı periferik arter ve karotis hastalığı gibi komorbid durumları belirlendi. İntraoperatif döneme ait; geçirdiği operasyon, aorta kros klemp (AKK) ve kardiyopulmoner bypass (KPB) süreleri, distal anastomoz sayısı, eşlik eden prosedürler ve kanama miktarı kaydedildi. Postoperatif döneme ait; inotrop desteği, intraaortik balon pompa gereksinimi (IABP), mekanik ventilasyon, yoğun bakımda ve hastanede kalış süreleri ile gelişen renal komplikasyon (serum kretininin $>1.5 \mathrm{gr} /$ dl ve dializ gereksinimi), nörolojik ve pulmoner komplikasyonlar (postoperatif solunum yetmezliği, pnömoni, plevral efüzyon, pnömotoraks), diyaliz ihtiyacl, atrial fibrilasyon, mediastinit, sternum revizyonu gereksinimi, tamponad ve kanama revizyonu gibi morbiditeler ve hastane mortalitesi sonuçları analiz edildi. Elde edilen analiz sonuçları Grup NO ve Grup $O B$ arasında değerlendirildi.

Tüm operasyonlar median sternotomi ile konvansiyonel kardiyak cerrahi prensipleri temel alınarak, orta dereceli sistemik hipotermi $\left(32^{\circ}\right)$ ve $2.0 \mathrm{~L} / \mathrm{dk} / \mathrm{m}^{2}$ - $2.4 \mathrm{~L} / \mathrm{dk} / \mathrm{m}^{2}$ pompa akımında, ortalama arteriyel basınç $55-70 \mathrm{mmHg}$ ve $\alpha$-stat kan yönetimi ile gerçekleştirilmişti. Myokardiyal koruma, prosedürel ihtiyaca göre antegrad (AKK sonrası $1000 \mathrm{~mL} / 25 \mathrm{mEq} / \mathrm{L}$ potasyum, $500 \mathrm{~mL} 20 \mathrm{dk}$ aralıklarla yinelenerek), devamlı retrograd veya her iki tekniğin birlikte kullanımıyla, soğuk veya izotermik, hiperpotasemik kan kardiyoplejisi ile sağlanmıştı. Antikoagülasyon için 300/400 ü/kg heparin, heparin nötralizasyonu için 1:1-1.5 oranında protamin kullanılmıştı.

Istatistiksel analizler NCSS (Number Cruncher 
Statistical System) 2007 Statistical Software (Utah, USA) paket programı kullanılarak yapıldı. Sürekli

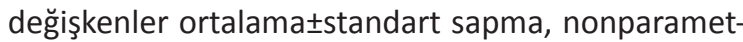
rik veriler ayrıca median (min-maks) ile tanımlandı. Kategorik veriler sayı ve yüzde olarak belirtildi. Gruplar arası karşıllaştırmada parametrik değişkenler, student $t$, nonparametrik değişkenler Mann Whitney $\mathrm{U}$ testi, kategorik veriler Fisher Exact testi ile değerlendirildi. Sonuçlar, $p<0.05$ düzeyinde istatistiksel olarak anlamlı kabul edildi.

\section{BULGULAR}

Çalışmamızda, retrospektif olarak incelenen 813 hastadan, intraoperatif ve postoperatif kayıtları eksiksiz olan 555 hastanın sonuçları değerlendirildi. Hastaların 389 'u (\%70) VKi $<30 \mathrm{~kg} / \mathrm{m}^{2}, 166$ 's। VKi $\geq 30 \mathrm{~kg} / \mathrm{m}^{2}$ obez olarak tespit edildi. Yaş ortalamaları Grup N'de ve Grup OB'de sırasıyla 59.2 $\pm 12.5,59.6 \pm 9.6$ yıldı ve gruplar arasında istatistiksel açıdan fark yoktu ( $p>$ 0.05, Tablo 1). Kadın cinsiyet Grup OB'de (66 \%40), Grup N'ye göre $(93 \% 23)$ anlamlı şekilde fazla bulundu ( $p<0.05$, Tablo 1). Sigara kullanımı Grup N'de anlamlı şekilde yüksekti ( $p=0.007)$. Yandaş hastalıklardan, HT, DM ve hiperlipidemi Grup OB'de anlamlı şekilde fazla iken $(p<0.001)$, diğer yandaş hastalıklar açısından iki grup benzerdi ( $p>0.05$, Tablo 1). Hastalara ait demografik özellikler ve eşlik eden hastalıklar Tablo 1'de gösterilmiştir.

Hastaların 70'i (\%12) acil olarak alınmış, 475'ine (\% 85) KABG, 26'sına (\%5) kapak (bir veya 2) ve 54 (\%9) hastaya eşlik eden prosedürler (Kapak+KABG, KABG+karotis, asendan aorta greft) uygulanmıştı.

Intraoperatif KPB ve AKK süreleri her iki grupta benzer bulundu ( $p>0.05$, Tablo 2 ).

Postoperatif pulmoner, renal komplikasyonlar, Grup OB'de, tamponad ve kanama revizyonu oranları ise Grup N'de anlamlı şekilde fazla bulundu $(p<0.05$, Tablo 3). Mekanik ventilasyon, yoğun bakım ve hastane kalış sürelerinde anlamlı farklılık yoktu ( $p>0.05$, Tablo 3). Otuz günlük mortalite oranı \%5 (27) olarak tespit edildi ve gruplar arasında mortalite oranları benzer bulundu ( $p>0.05$, Tablo 3 ).

\section{Tablo 1. Demografik veriler ve yandaş hastalıklar.}

\begin{tabular}{|c|c|c|c|}
\hline & $\begin{array}{c}\text { Grup N } \\
n=389(70) \\
n(\%), \text { Ort } \pm S D\end{array}$ & $\begin{array}{c}\text { Grup OB } \\
n=166(30) \\
n(\%), \text { Ort } \pm S D\end{array}$ & $\mathbf{p}$ \\
\hline Cinsiyet; Erkek/Kadın & 296 (77) / 93 (23) & $100(60) / 66(40)$ & $<0.001^{\mathrm{a}}$ \\
\hline Yaş (yıl) & $59.2 \pm 12.5$ & $59.6 \pm 9.6$ & 0.65 \\
\hline VKi $\left(\mathrm{kg} / \mathrm{m}^{2}\right)$ & $25.58 \pm 2.85$ & $32.49 \pm 2.70$ & $<0.001^{b}$ \\
\hline \multicolumn{4}{|l|}{ ASA } \\
\hline I & $18(4.6)$ & - & \\
\hline II & $228(58.6)$ & $93(56)$ & \\
\hline III & $135(34.7)$ & $72(43.4)$ & \\
\hline IV & $8(2.1)$ & $1(0.6)$ & \\
\hline HT & $192(48)$ & $110(66)$ & $<0.001^{a}$ \\
\hline DM & $121(31)$ & $80(48)$ & $<0.001^{\mathrm{a}}$ \\
\hline KOAH & $88(22.5)$ & $43(26)$ & 0.41 \\
\hline Geçirilmiş SVO & $36(9)$ & $16(9)$ & 0.92 \\
\hline $\mathrm{EF} \%$ & $51.4 \pm 9$ & $51.8 \pm 8.6$ & 0.62 \\
\hline Geçirilmiş MI & $104(26.7)$ & $39(23.4)$ & 0.4 \\
\hline KBY & $15(3)$ & $9(5)$ & 0.80 \\
\hline Hiperlipidemi & $194(50)$ & $101(60.1)$ & $0.02^{\mathrm{a}}$ \\
\hline Perifer arter hastalı̆̆ı & 41 (10.5) & $15(9)$ & 0.59 \\
\hline Karotis arter hastalığı & $33(8)$ & $9(5)$ & 0.29 \\
\hline Sigara & $201(52)$ & 65 (39) & $0.007^{a}$ \\
\hline
\end{tabular}

VKi: Vücut kitle indeksi, ASA: American Society of Anesthsiologist, HT: Hipertansiyon, DM: Diabetes Mellitus, KOAH: Kronik obstrüktif akciğer hastalığı, SVO: Serebrovasküler atak, EF: Ejeksiyon fraksiyonu, MI: Myokard infarktüsü, ${ }^{a}$ Fisher exact, ${ }^{b}$ student $t$ test, $p<0.05$ 
Tablo 2. Operatif özellikler.

\begin{tabular}{|c|c|c|c|}
\hline & $\begin{array}{c}\text { Grup N } n=389(70) \\
n(\%), \text { Ort } \pm S D \\
\text { Median (min-maks) }\end{array}$ & $\begin{array}{c}\text { Grup OB } n=166(30) \\
n(\%), \text { Ort } \pm S D \\
\text { Median (min-maks) }\end{array}$ & $\mathbf{p}$ \\
\hline Acil operasyon & $44(11)$ & $26(15)$ & 0.16 \\
\hline KABG & $329(85)$ & $146(88)$ & 0.36 \\
\hline Kapak & $18(4)$ & $8(5)$ & 0.55 \\
\hline Eşlik eden prosedürler & $40(10)$ & $14(9)$ & 0.61 \\
\hline KPB süresi (dak) & $\begin{array}{c}101 \pm 43 \\
94.5(22-440)\end{array}$ & $\begin{array}{c}98 \pm 42 \\
93.5(34-314)\end{array}$ & 0.26 \\
\hline AKK süresi (dak) & $\begin{array}{c}64 \pm 32.7 \\
57.5(9-235)\end{array}$ & $\begin{array}{c}61.6 \pm 32.5 \\
53.5(15-341)\end{array}$ & 0.21 \\
\hline Distal anastomoz sayısı & $3.1 \pm 1.0(1-6)$ & $3.2 \pm 1.0(1-6)$ & 0.92 \\
\hline
\end{tabular}

KPB; Kardiyopulmoner baypas süresi, AKK: Aorta kross klemp süresi, KABG: Koroner arter baypas greftleme,

Eşlik eden prosedürler; Kapak+KABG, Asendan Aort Greft+KABG, Karotis+KABG

Tablo 3. Postoperatif sonuçlar.

\begin{tabular}{|c|c|c|c|}
\hline & $\begin{array}{c}\text { Grup N n=389 (70) } \\
n(\%), \text { Ort } \pm S D, \\
\text { Median (min-maks) }\end{array}$ & $\begin{array}{c}\text { Grup OB n=166 (30) } \\
n(\%), \text { Ort } \pm S D, \\
\text { Median (min-maks) }\end{array}$ & p \\
\hline Pulmoner komplikasyonlar & $40(10)$ & $34(20)$ & $0.030^{\mathrm{a}}$ \\
\hline $\mathrm{AF}$ & $58(15)$ & $26(15)$ & 0.87 \\
\hline Renal komplikasyonlar & $34(9)$ & $22(13)$ & $0.032^{\mathrm{a}}$ \\
\hline Diyaliz gereksinimi & $16(4)$ & $9(5)$ & 0.305 \\
\hline Tamponad & $12(3.1)$ & $1(0.6)$ & $0.042^{a}$ \\
\hline Kanama revizyonu & $21(5.3)$ & $3(1.8)$ & $0.046^{\mathrm{a}}$ \\
\hline Yüzeysel enfeksiyon & $30(7.7)$ & $13(7.8)$ & 0.60 \\
\hline Mediastinit & $4(1)$ & $3(1)$ & 0.45 \\
\hline Sternum revizyonu & $6(1.5)$ & $6(3.5)$ & 0.25 \\
\hline GiS komplikasyonlar & $14(3.5)$ & $9(5)$ & 0.191 \\
\hline SVO & $5(1.2)$ & $3(1)$ & 0.63 \\
\hline İnotrop gereksinimi & $88(23)$ & $68(20)$ & 0.35 \\
\hline IABP & $15(3.8)$ & $5(3)$ & 0.848 \\
\hline Postoperatif drenaj & $\begin{array}{c}584 \pm 313 \\
500(50-4000)\end{array}$ & $\begin{array}{c}580.6 \pm 319 \\
500(50-2000)\end{array}$ & 0.83 \\
\hline MVS (saat) & $8.6 \pm 4.4(3-48)$ & $9.6 \pm 7(4-72)$ & 0.12 \\
\hline YBÜ kalış (gün) & $3.7 \pm 3.1(1-28)$ & $4.8 \pm 4.7(1-45)$ & 0.25 \\
\hline Postoperatif hastane kalış (gün) & $5.3 \pm 4.9(1-44)$ & $5.4 \pm 3.8(1-30)$ & 0.43 \\
\hline Mortalite & $19(5)$ & $8(5)$ & 0.98 \\
\hline
\end{tabular}

AF: Atrial fibrilasyon, SVO: Serebrovasküler olay, iABP:intraaortik balon pompa, GiS: Gastointestinal, MVS: Mekanik ventilasyon süresi ${ }^{a}$ Fisher exact $p<0.05$ 


\section{TARTIŞMA}

Obezite pek çok organ ve sistemi önemli derecede etkileyerek hipertansiyon, diabetes mellitus ve $\mathrm{KOAH}$ gibi perioperatif komplikasyon oranlarını arttıran risk faktörlerine neden olur. Literatürde kardiyovasküler cerrahi için refere edilen obez olgularda, preoperatif hipertansiyon, diabetes mellitus, kronik akciğer hastalıkları ve hiperlipidemi insidansının daha yüksek oranlarda bulunduğu, yaş aralığı olarak daha genç oldukları ve kadın cinsiyetin daha fazla olduğu gösterilmiştir ${ }^{[5,8,9,13]}$. Bizim çalışmamızda da obez grupta hipertansiyon, diyabet gibi yandaş hastalıklar ve kadın cinsiyet daha fazla iken, yaş aralıkları benzerdi.

Kalp cerrahisi sonrası, obezitenin solunum sistemine etkileri en fazla endişe duyulan sorunlardandır ve birçok nedenle meydana gelir. Obezitenin solunum sistemi üzerinde, düşük fonksiyonel rezidüel kapasite, ventilasyon/perfüzyon uyumsuzluğu ve solunum kas gücünde zayıflık gibi negatif etkileri olduğu ve tüm bunların kalp cerrahisi sonrası pulmoner komplikasyonları arttırdığı bildirilmiştir [5,7,8,14]. Ek olarak, kalp cerrahisinde uygulanan mediyan sternotomi ve kardiyopulmoner baypas dinamiklerinin patolojik etkileri postoperatif dönemde hastaları pnömoni, atelaktazi gibi solunum sistemi komplikasyonlarına yatkın hale getirirerek uzayan mekanik ventilasyon, YBÜ ve hastane kalış süreçlerine neden olur ${ }^{[5,14]}$. Demir ve ark. ${ }^{[8]}$ VKi $\geq 35 \mathrm{~kg} / \mathrm{m}^{2}$, Alam ve ark. ${ }^{[15]}$ VKi $\geq 30 \mathrm{~kg} / \mathrm{m}^{2}$ olan obez olgularda postoperatif solunum sistemi komplikasyonlarının daha fazla görüldüğünü, ancak mekanik ventilasyon, YBÜ ve hastane kalış süreçlerinde anlamlı farklılık olmadığını bildirmişlerdir. Gürbüz ve ark. ${ }^{[13]}$ da VKi $\geq 30 \mathrm{~kg} / \mathrm{m}^{2}$ olgularda ventilasyon süresinin uzadığını ancak alt grup analizinde anlamlı farklılık olmadığını, hastane ve YBÜ kalış sürelerinin benzer olduğunu göstermişler ve bu durumu benzer AKK/KPB sürelerine dayandırmışlardır. Bizim çalışmamızda AKK/KBP süreleri açısından gruplar arasında anlamlı fark yoktu ve postoperatif solunum komplikasyonları obez grupta daha fazla gözlenirken, mekanik ventilasyon, YBÜ ve hastane kalış süreleri açısından gruplar benzer bulundu.
Kalp cerrahisi sonrası hasta sonuçlarını etkileyen önemli komplikasyonlardan biri de postoperatif böbrek yetmezliğidir ve literatürde sıklığının obezite ile arttığı, ancak diyaliz gereksiniminde anlamlı fark olmadığı gösterilmiştir [5,13,15-17]. Mekanizması net olmasa da, değişen renin-anjiotensin-aldesteron sistemi, kronik inflamasyon, metabolik sendrom ve preoperatif HT/DM gibi komorbiditelerin varlığı suçlanmaktadır ${ }^{[5,16,17]}$. Sonuçlarımız da literatürle benzer şekilde postoperatif obez grupta renal yetmezlik insidansı yüksek, dializ gereksinimi benzer bulundu.

Obezitenin postoperatif kanama için koruyucu etkisi olduğu bildirilmiştir ${ }^{[5]}$. Ghanta ve ark. ${ }^{[5]} 13637$ hastalık çalışmada obez ve morbid obez grupta daha az kanama ve kan ürünü kullanımı gerektiğini göstermişlerdir. Yine iki farklı çalışmada da, obez olgularda kanama komplikasyonu ve buna bağlı re-operasyon oranlarının daha az olduğu gösterilmiştir ${ }^{[15,18]}$. Pek çok çalışmada obezitenin daha az kanamayla ilişkisi gösterilmiş ve bunun nedeni olarak, mediastende biriken büyük miktardaki yağ dokusu ve yüksek intraabdominal basıncın, intratorasik basıncı arttırarak kanama alanlarında kompresyon etkisi yaratması, açıklık kazanmasa da obeziteye bağlı hiperkoagülopatik durum ve daha az hemodilüsyon gereksinimi olarak bildirilmiştir ${ }^{[5,13-15,17,18]}$. Bizim çalışmamızda da postoperatif drenaj miktarları benzer olsa da tamponad ve kanama sebepli cerrahi gereksinim obez grupta daha azdı.

Obesite, hem yüzeysel hem derin, sternal ve safen bölgesi gibi cerrahi alan enfeksiyonları ve mediastinit gelişimi için bağımsız risk faktörüdür. Yağ dokunun daha az kanlanması ve eşlik eden ve kontrolsüz DM varlığı bu durumu kolaylaştırır ${ }^{[12,15,17]}$. Gürbüz ve ark. obezitenin yara yeri enfeksiyonları ve mediastinit riskini 6.9 kat, sternal ayrılma riskini 21 arttırdığını bildirmişlerdir ${ }^{[13]}$. Wigfield ve ark. ${ }^{[19]}$ ise çalışmalarında, obezite ile derin veya yüzeyel enfeksiyöz komplikasyonlarda farklılık göstermemiş, bu durumun nedenini yüksek oranda obez olgu deneyimleri olarak belirtmiştir. Çalışmamızda obezite ile yara yeri enfeksiyonları, mediastinit ve sternum revizyonu 
oranlarında farklılık gözlenmedi. Bunun nedeni, klinik rutinimizde diabetik hastaların perioperatif kan şekerlerinin yakın takip edilmesi, kan şekeri için 180200 mg/dL sınırının aşıımamasına dikkat edilmesi ve obez olgularda cerrahi kapama şekli olarak Robiscek tekniğinin sıklıkla tercih edilmesi olabilir.

Kardiyak cerrahiye gelen obez hastalara geleneksel olarak mortalite ve morbidite açısından yüksek riskli olarak bakılır. Kalp cerrahisinde obezite ve hasta sonuçları arasındaki ilişki pek çok çalışmada değerlendirilmiş, pek çoğunda obezitenin erken mortaliteyle ilişkili olmadığı gösterilmiştir ${ }^{[8,12,19]}$. Hartrumpf ve ark. ${ }^{[20]} 15000$ hastalık çalışmalarında obezitenin erken mortalitede risk faktörü olmadığı gibi protektif etkileri olduğunu bildirmişlerdir. Ulusal erişkin kalp cerrahisi grubunun (NASCA) çalışmasında da obezitenin düşük risk faktörü olduğu, protektif etki gösterdiği ve mortalitenin düşük VKi durumunda arttığı vurgulanmıştır [21]. Bizim çalışmamızda da obezite ile mortalite artışı gözlenmedi. Mortalite gelişimi her iki grupta benzer bulundu.

Sonuç olarak, perioperatif bakımdaki tüm iyileşme ve gelişmelere rağmen obezite, kalp cerrahisi sonrası morbidite gelişimi için risk faktörü olmaya devam etmektedir. Çalışmamızda da obez ve obez olmayan olgularda mortalite oranları benzer bulunurken, obez olgularda solunum sistemi ve renal komplikasyonlar daha yüksek oranda gözlendi. Bu nedenle bu olgularda perioperatif hemodinamik takip ve solunum sistemi fonksiyonları için yoğun rehabilitasyonun önemli olduğunu düşünmekteyiz.

\section{KAYNAKLAR}

1. WHO - World Health Organization. Obesity and overweight 2010. Updated June 2016.

2. McLellan F. Obesity rising to alarming levels around the world. Lancet. 2002;359:1412. https://doi.org/10.1016/S0140-6736(02)08397-6

3. Hubert HB, Feinleib M, McNamara PM, Castelli WP. Obesity as an independent risk factor for cardiovascular disease: A 26-year follow-up of participants in the Framingham Heart Study. Circulation 1983;67:968-77. https://doi.org/10.1161/01.CIR.67.5.968

4. Nahar N, Dubey S, Joshi A, Phadnis S, Sharma VK.
Association of anthropometric indices of obesity with diabetes, hypertension and dyslipidemia: a study from central India. Indian Journal of Medical Specialties 2012;3(1):6-11.

https://doi.org/10.7713/ijms.2012.0003

5. Ghanta RK, LaPar DJ, Zhang Q, Devarkonda V, Isbell JM, Yarboro LT, et al. Obesity increases risk-adjusted morbidity, mortality, and cost following cardiac surgery. Am Heart Assoc. 2017;6:e003831. https://doi.org/10.1161/JAHA.116.003831

6. Habib RH, Zacharias A, Schwann TA, Riordan CJ, Durham SJ, Shah A. Effects of obesity and small body size on operative and long-term outcomes of coronary artery bypass surgery: a propensity-matched analysis. Ann Thorac Surg. 2005;79:1976-86. https://doi.org/10.1016/j.athoracsur.2004.11.029

7. Rahmanian PB, Adams DH, Castillo JG, Chikwe J, Bodian CA, Filsoufi F. Impact of body mass index on early outcome and late survival in patients undergoing coronary artery bypass grafting or valve surgery or both. Am J Cardiol. 2007;100:1702-8.

https://doi.org/10.1016/j.amjcard.2007.07.017

8. Demir A, Aydınlı B, Güçlü ÇY, Yazıcıoğlı H, Sarac A, Elhan $\mathrm{AH}$, et al. Obesity and postoperative early complications in open heart surgery. J Anesth. 2012;26:702-10. https://doi.org/10.1007/s00540-012-1393-7

9. Atalan N, Fazliogulları O, Kunt AT, Basaran C, Gürer O, Şitilci T, et al. Effect of body mass index on early morbidity and mortality after isolated coronary artery bypass graft surgery, J Cardiothorac Vasc Anesth. 2012;26(5): 813-7.

https://doi.org/10.1053/j.jvca.2012.01.033

10. Stamou SC, Nussbaum M, Stiegel RM, Reames MK, Skipper ER, Robicsek F, et al. Effect of body mass index on outcomes after cardiac surgery: is there an obesity paradox? Ann Thorac Surg. 2011;91:42-7. https://doi.org/10.1016/j.athoracsur.2010.08.047

11. Reeves BC, Ascione R, Chamberlain MH, Angelini GD. Effect of body mass index on early outcomes in patients undergoing coronary artery bypass surgery. J Am Coll Cardiol. 2003;42:668676. https://doi.org/10.1016/S0735-1097(03)00777-0

12. Organization WH. WHO global database on body mass index (BMI). An interactive surveillance tool for monitoring nutrition transition 2006.

13. Gürbüz $H A$, Durukan $A B$, Salman $N$, Uçar $H i$, Yorgancıoğlu C. Obesity is still a risk factor in coronary artery bypass surgery. Anadolu Kardiyol Derg. 2014;14:631-7. https://doi.org/10.5152/akd.2014.4954

14. Saraç ŞB, Örki TK, Erkılınç A, Oğuş H, Yatırık R, Güzelmeriç F, Koçak T. On-pump koroner arter baypas greftleme (KABG) ameliyatı geçiren hastalarda metabolik sendromun pulmoner komplikasyonlar üzerine etkisi. GKDA Derg. 2013;19(2):76-9. https://doi.org/10.5222/GKDAD.2013.076

15. Alam M, Siddiqui S, Lee W, Elayda MA, Nambi V, Yang $E Y$, et al. Isolated coronary artery bypass grafting in 
obese individuals: a propensity matched analysis of outcomes. Circ J. 2011;75:1378-85.

https://doi.org/10.1253/circj.CJ-10-1129

16. O'Sullivan KE, Byrne JS, Hudson A, Murphy AM, Sadlier DM, Hurley JP. The effect of obesity on acute kidney injury after cardiac surgery. J Thorac Cardiovasc Surg. 2015;150:1622-8.

https://doi.org/10.1016/j.jtcvs.2015.08.082

17. De Santo LS, Moscariello C, Zebele C. Implications of obesity in cardiac surgery: pattern of referral, physiopathology, complications, prognosis. J Thorac Dis. 2018;10(7):4532-39.

https://doi.org/10.21037/jtd.2018.06.104

18. Wang $M$, Chen $M, A o H$, et al. The effects of different $\mathrm{BMI}$ on blood loss and transfusions in chinese patients undergoing coronary artery bypass grafting. Ann Thorac Cardiovasc Surg. 2017;23:83-90. https://doi.org/10.5761/atcs.oa.16-00219

19. Wigfield CH, Lindsey JD, Munoz A, Chopra PS, Edwards NM, Lov RB. Is extreme obesity a risk factor for cardiac surgery? An analysis of patients with a BMI $\geq 40$ Eur J Cardiothorac Surg. 2006;29:434-40. https://doi.org/10.1016/j.ejcts.2006.01.016

20. Hartrumpf M, Kuehnel RU, Albes JM. The obesity paradox is still there: A risk analysis of over 15000 cardiosurgical patients based on body mass index. Interact Cardiovasc Thorac Surg. 2017;25:18-24. https://doi.org/10.1093/icvts/ivx058

21. Mariscalco G, Wozniak MJ, Dawson AG, Serraino GF, Porter R, Nath M. Body Mass Index and Mortality Among Adults Undergoing Cardiac Surgery A nationwide study with a systematic review and meta-analysis. Circulation 2017;135:850-63.

https://doi.org/10.1161/CIRCULATIONAHA.116.022840 